\title{
From stalled progress to epic wins
}

\author{
Global energy sector emissions have stalled. But urgent questions remain about the best way to tackle \\ climate change.
}

Emissions of $\mathrm{CO}_{2}$ from the energy sector plateaued in 2014, according to new figures from the International Energy Agency ${ }^{1}$. It's the first time in 40 years that emissions have failed to rise in the absence of an economic crisis. The UK's Financial Times, which first reported the story, said the data shows "that efforts to tackle climate change may have been more effective than thought" 2 .

But without further efforts to significantly cut emissions, 2014 will be little more than a blip in an otherwise alarming trend. The IEA's Executive Director, Maria van der Hoeven, said in a statement that "this is no time for complacency - and certainly not the time to use this positive news as an excuse to stall further action"1.

Indeed, the IPCC identifies a 'carbon budget' that implies around two-thirds of the world's known fossil fuel reserves will have to remain unburned if the world is going to have a 'decent' chance of avoiding warming of more than $2{ }^{\circ} \mathrm{C}$ (ref. 3). Once non-energy sector emissions are included in the calculation, the budget implies a global emissions cut across all sectors of about 40 to $70 \%$ from 2010 levels by $2050^{4}$.

There are still fundamental questions remaining about how the world can achieve those cuts.

The media's obsession with trying to explain who or what was responsible for 2014's stall - with prevalent theories being reduced consumption in China and continual growth in renewable energy capacity in OECD countries - shows that measuring emissions remains integral to transparent climate policy. But disagreements remain about how best to calculate emissions.

Whether countries should be held to account for greenhouse-gas emissions originating within their borders, or take additional responsibility for those embedded in their imports, remains a source of debate. In this issue, Astrid Kander and colleagues suggest a further measurement, tweaking consumption based emissions estimates to allow for technological advances. They show how carbon accounting choices have the potential to redraw the emissions map (p431).

Even if it remains unclear how countries' emissions will be measured, all will ultimately have to work to reduce them.

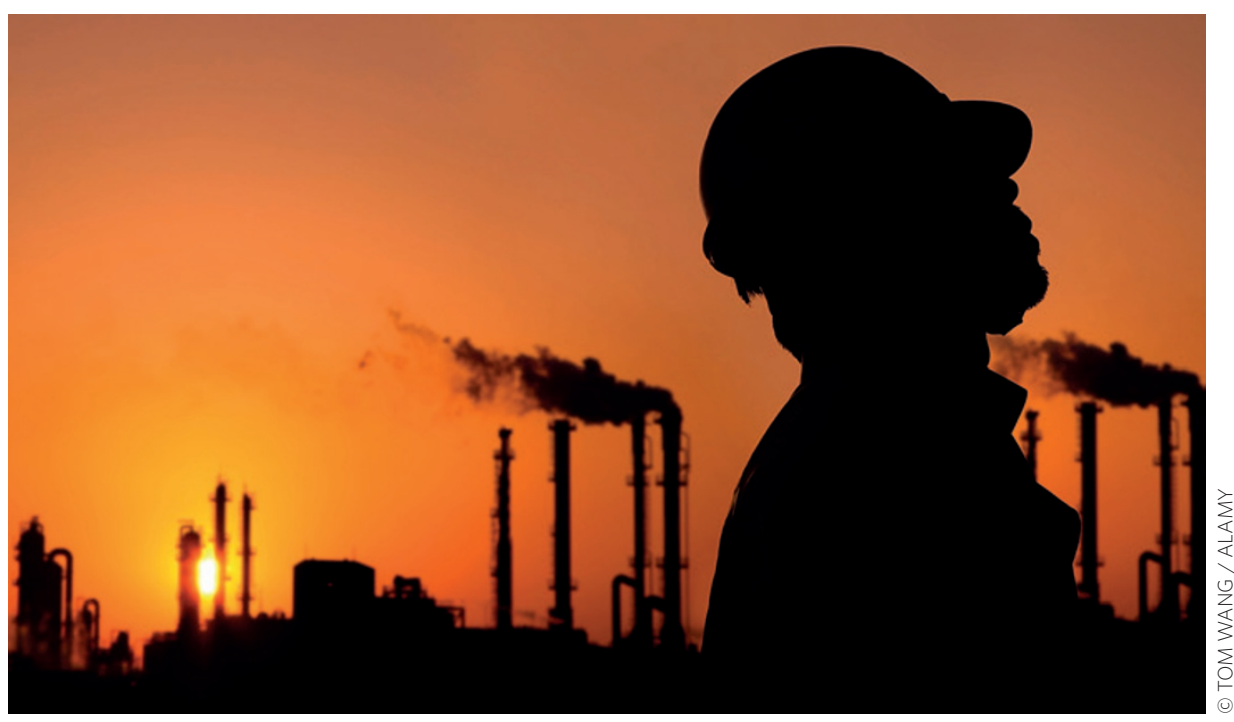

A top priority will be decisions over the future of fossil fuels. The long-term future of coal, oil, and gas hinges on the feasibility of carbon capture and storage technology, assuming the world commits to the IPCC's carbon budget. Capturing power plants' emissions has often been seen as the largest challenge, but a Perspective from Vivian Scott and colleagues (p419) argues there may be as many complications with storage. If the world wants to continue burning coal, biomass and unconventional fossil-fuels consistent with current rates, additional storage options will need to be found and engineered, implying radical innovation in the coming years.

Implementing robust carbon pricing will form an essential part of any strategy to wean the world off these fuels. But fundamental debates remain over whether carbon prices should be an 'objective' or 'instrument' of stringent climate policy, as Joseph Aldy argues in a Commentary (p396). Even if policymakers agree with carbon pricing in principle, debates over what level it should be set at continue to rage. Thomas Lontzek and colleagues (p441) show that once the uncertainties around singular, large scale events - or climatic 'tipping points' - are considered, the optimal carbon price could be as much as $200 \%$ higher than current levels.

Public pressure will be necessary to get policymakers to even consider such strategies. But engaging the public continues to prove difficult. UK newspaper The Guardian recently launched a campaign to try and harness public support for 'divestment' - a strategy it hopes will "delegitimise the business models of companies that are using investors' money to search for yet more coal, oil and gas that can't safely be burned"5. But for people to back such campaigns, they first have to care about climate change.

That means using new, unconventional tools to engage and educate them. Jason $\mathrm{Wu}$ and Joey Lee look at climate change games that seek to do just that (p413). Giving people virtual "firsthand experience" of climate change, and the opportunity to control the factors that drive it such as energy policy, promotes belief that "an epic win is always possible", they argue.

Continuing to probe and question the best path to such 'victories' will be essential if the world is going to turn stalled emissions into rapid reductions.

\footnotetext{
References

1. Global energy-related emissions of carbon dioxide stalled in 2014 IEA (13 March 2015); http://go.nature.com/YuZYhh

2. Clarke, P. Clobal carbon emissions stall in 2014. Financial Times (12 March 2015); http://go.nature.com/AFac6a

3. McGlade, C. \& Ekins, P. Nature 517, 187-190 (2015).

4. IPCC Summary for Policymakers in Climate Change 2014: Synthesis Report (eds Pachauri, R., Meyer, L. \& Core Writing Team) (Intergovernmental Panel on Climate Change, 2014).

5. Rusbridger, A. The argument for divesting from fossil fuels is becoming overwhelming. The Guardian (16 March 2015); http://go.nature.com/a5Ox97
} 